\title{
QUALIDADE MICROBIOLÓGICA DE ÁGUAS DE COCO COMERCIALIZADAS NO MUNICÍPIO DE CURRAIS NOVOS/RN
}

\author{
Jonas Luiz Almada da Silva \\ Engenheiro de Alimentos, Mestre em Ciência e Tecnologia de Alimentos, Prof. do IFRN - \\ Campus Currais Novos. E-mail: jonasalmada@cefetrn.br
}

Fabriny Aprígio Vieira Dantas

Aluno do curso Técnico em Alimentos do IFRN - Campus Currais Novos, E-mail: fabriny_aprigio@hotmail.com

Fábia Costa Silva

Aluno do curso Técnico em Alimentos do IFRN - Campus Currais Novos, E-mail:

flaveuts@hotmail.com

\begin{abstract}
RESUMO
A água de coco é uma bebida obtida do fruto verde de coqueiro, sendo um líquido refrescante, isotônico e cada vez mais consumido por suas características organolépticas e nutricionais. As etapas de extração e engarrafamento são bastante susceptíveis ao ataque microbiano resultando em perda da qualidade do produto e conseqüente diminuição do seu valor comercial. O presente trabalho teve como objetivo verificar a qualidade microbiológica da água de coco engarrafada e comercializada na cidade de Currais Novos/RN. Observou-se que, das 22 amostras analisadas, a presença de coliformes totais foi verificada em $82 \%$ das amostras (dezoito amostras) sugerindo o contato do coco com o habitat da referida bactéria bem como falhas no processo de higienização do fruto. Com relação à contagem de coliformes fecais, 22,7\% apresentava-se fora dos padrões estabelecidos pela Legislação Brasileira, no entanto não foi constatada a presença de Salmonella sp e Staphylococcus coagulase positiva. Bactérias mesófilas e bolores e leveduras foram encontrados em níveis de $6,0 \times 10 \mathrm{UFC} / \mathrm{mL}$ a 3,0 $010^{5} \mathrm{UFC} / \mathrm{mL}$ e de zero a $1,7 \times 10^{5}$ respectivamente, sugerindo a necessidade de melhorias durante o processo de envase de água de coco verde resfriada.
\end{abstract}

PALAVRAS-CHAVE: água de coco, qualidade, microbiológica

\section{MICROBIOLOGY QUALITY OF COCONUT WATERS COMMERCED IN THE CURRAIS NOVOS/RN CITY}

\begin{abstract}
The coconut water is a drink obtained of the green fruit of the coconut tree, it's a freshly liquid, isotonic and ever more consumed for the organoleptic and nutritional characteristics. The steps of extraction and bottling are very susceptible to microbial attack resulting in loss of product quality and consequent reduction of its commercial value. This study aimed to verify the microbiological quality of bottled coconut water and marketed in the city of New Currais / RN. It was observed that of the 22 samples analyzed, the presence of total coliform was detected in $82 \%$ of samples (eighteen samples) suggesting contact of the coconut with the bacteria habitat as well as flaws in the process of cleaning
\end{abstract}


the fruit. With respect to the counting of fecal coliforms, $22.7 \%$ were outside the standards established by Brazilian legislation, however was not the presence of Salmonella sp. and Staphylococcus coagulase positive. Mesophilic bacteria and yeasts and molds were found at levels of $6.0 \times 10 \mathrm{CFU} / \mathrm{mL}$ to $3.0 \times 10^{5} \mathrm{CFU} / \mathrm{mL}$ and from zero to $1.7 \times 10^{5}$ respectively, suggesting the need for improvements during the filling of green coconut water cooled.

WORD-KEYS: coconut water, quality, microbiology 


\section{INTRODUÇÃO}

Atualmente, com a contribuição dos avanços na área da Tecnologia dos Alimentos, o homem tem buscado alimentos cada vez mais saudáveis, com maior tempo de conservação e maior praticidade no consumo do dia-a-dia.

A água de coco envasada vem apresentando um considerável crescimento do seu consumo, por ser uma bebida com características nutricionais e sensoriais adequadas, é um produto natural, pouco calórico, com sabor agradável, conhecido mundialmente e muito apreciado em todo o Brasil, principalmente nas regiões litorâneas. (ARAGÃO, 2000; AROUCHA \& VIANNI, 2002; PENHA, 1998).

Corresponde a aproximadamente $25 \%$ do peso do fruto, e sua composição básica apresenta 93\% de água, 5\% de açúcares, além de proteínas, vitaminas e sais minerais. A composição química média, no período ótimo de colheita do fruto para água de coco, é a seguinte: $\mathrm{pH}$ 4,8; calorias 18,1; acidez 1,3ml de sol normal $/ 100 \mathrm{ml}$; grau Brix $\left(21^{\circ} \mathrm{C}\right) 7,0$; glicose 4,4g/100ml; proteínas 0,37mg; fósforo 6,2mg/100ml; potássio $175 \mathrm{mg} / 100 \mathrm{ml}$; cálcio $17,5 \mathrm{mg} / 100 \mathrm{ml}$; magnésio $8,5 \mathrm{mg} / 100 \mathrm{ml}$; sódio $10,5 \mathrm{mg} / 100 \mathrm{ml}$; ferro $0,06 \mathrm{mg} / 100 \mathrm{ml}$; vitamina C 57mg/100g. (NOGUEIRA, 2004).

Atualmente, a água de coco verde consiste em um grande ramo de comercialização de cocos da variedade anã verde, com acessos notadamente a mercados distantes dos centros produtores. Tradicionalmente, a água de coco é comercializada dentro do próprio fruto, prática que envolve problemas relacionados a transporte, armazenamento e perecibilidade do produto.

Sua industrialização é de fundamental importância, pois permite o seu consumo em locais fora das regiões produtoras, visando diminuir o volume e o peso transportados e, conseqüentemente, reduzir os custos de transporte, bem como aumentar a sua vida de prateleira (ABREU, 2008).

Estima-se um aumento de cerca de $20 \%$ ao ano no consumo de água de coco in natura no Brasil. Sua facilidade de comercialização e consumo se deve ao seu baixo custo atingindo a todas as classes sociais.

Segundo Hoffman (2002) a água de coco é considerada uma bebida estéril, porém, o contato com o ambiente, utensílios e equipamentos e manipuladores sem a devida higienização podem torná-la imprópria para o consumo diminuindo sua qualidade, levando inclusive, a ser uma fonte de contaminação por microrganismos patogênicos.

Campos (1996) afirma que aliadas às alterações de ordem microbiana, as alterações bioquímicas também contribuem para a diminuição da qualidade do produto, proporcionando modificações de cor e sabor decorrentes da ação de enzimas tais como as polifenoloxidases e peroxidases.

Dentro deste contexto o presente trabalho objetivou a avaliação da qualidade das águas de coco produzidas e comercializadas na cidade de Currais Novos/RN, sob o ponto de vista microbiológico, comparando com os padrões estabelecidos pela Legislação vigente.

\section{MATERIAL E MÉTODOS}




\subsection{MATERIAL}

Foram coletadas 22 amostras, durante o período de abril a dezembro de 2008, de águas de coco envasadas e comercializadas no município de Currais Novos/RN.

As amostras foram conduzidas ao laboratório de Alimentos no IFRN - Campus de Currais Novos, em caixa isotérmica e submetidas às análises de coliformes totais e fecais, contagem em placas de bactérias mesófilas e bolores e leveduras, Salmonella sp. e contagem de Staphylococcus coagulase positiva.

\subsection{MÉTODOS}

\subsubsection{Preparo das amostras}

Foi retirada uma alíquota de $25 \mathrm{~mL}$ da amostra coletada e transferida, assepticamente, para um erlenmeyer contendo $225 \mathrm{~mL}$ de salina peptonada estéril, obtendo-se a primeira diluição $\left(10^{-1}\right)$. Desta diluição foi retirado $1 \mathrm{~mL}$ e transferido para um tubo de ensaio contendo $9 \mathrm{~mL}$ de salina peptonada obtendo-se a segunda diluição $\left(10^{-2}\right)$ e a partir desta a terceira diluição $\left(10^{-3}\right)$.

\subsubsection{Análises microbiológicas}

A partir das diluições preparadas foram realizadas as análises de coliformes fecais e totais, contagem em placa de bolores e leveduras e bactérias mesófilas totais, detecção de Salmonella sp. e contagem de Staphylococcus coagulase positiva.

Para a análise de coliformes totais e fecais foi utilizada a técnica do Número Mais Provável $(\mathrm{NMP} / \mathrm{mL})$, sendo utilizados os meios, caldo lauril sulfato triptose e caldo bile verde brilhante na etapa presuntiva, com incubação a $35-37^{\circ} \mathrm{C}$ por $24-48 \mathrm{~h}$ e caldo EC na etapa confirmativa para coliformes fecais, sendo esta última etapa incubada em banho-maria a $45,5^{\circ} \mathrm{C} / 24 \mathrm{~h}$. Provas bioquímcas da série IMViC foram realizadas para a caracterização das provas positivas para coliformes fecais e detecção de Escherichia coli.

Amostras com resultado positivo para coliformes fecais foram também submetidas a detecção de Salmonella sp. de acordo com método recomendado por SILVA (2007).

A contagem de bolores e leveduras foi realizada em duplicata, utilizando a técnica de plaqueamento em superfície, sendo as amostras diluídas inoculadas $(0,1 \mathrm{~mL})$ em placas, previamente preparadas, contendo ágar batata dextrose, acidificado com ácido tartárico $10 \%$ em pH 3,5. A incubação foi feita em estufa BOD com temperatura controlada a $25^{\circ} \mathrm{C}$ por 3 a 5 dias.

As contagens de bactérias mesófilas totais foram realizadas por plaqueamento, em duplicata, em profundidade onde se utilizou $1 \mathrm{~mL}$ de cada diluição sendo inoculados em placas estéreis e vertidos nas mesmas Agar padrão para contagem e incubadas a 35$37^{\circ} \mathrm{C} / 24 \mathrm{~h}$.

Staphylococcus coagulase positiva foram analisados por plaqueamento em superfície, utilizando agar Baird-Parker suplementado com telurito de potássio 3,5\% e emulsão de gema de ovo, a incubação foi realizada em estufa bacteriológica a $35-37^{\circ} \mathrm{C} / 24 \mathrm{~h}$. Colônias positivas (pontos negros com halo de inibição ao redor) foram submetidas ao teste de coagulase utilizando-se plasma de coelho liofilizado ressuspendido em água destilada estéril. 


\section{RESULTADOS E DISCUSSÃO}

Das 22 amostras analisadas verificou-se que 22,7\% (cinco amostras) apresentavam-se contaminadas por coliformes fecais (Figura 2) apresentando-se fora dos padrões estabelecidos pela legislação vigente que é de 100NMP/mL (BRASIL, 2001). A presença de coliformes fecais indica que houve, no produto ou durante o processo, contato direto ou indireto com fezes humanas ou de animais de sangue quente caracterizando uma deficiência na manipulação ou má higienização da matéria-prima.

Coliformes totais foram percebidos em $82 \%$ das amostras analisadas (dezoito amostras) sugerindo o contato do coco com o solo, visto que, a maioria dos estabelecimentos produtores não utiliza a etapa de lavagem com sanificante, a qual retira os resíduos sólidos evitando acabar e/ou reduzir os problemas relacionados com a contaminação microbiana proveniente do solo, ou ausência de boas práticas de higiene. Não foi encontrada a presença de Salmonella sp. em nenhuma das amostras (Tabela 1).

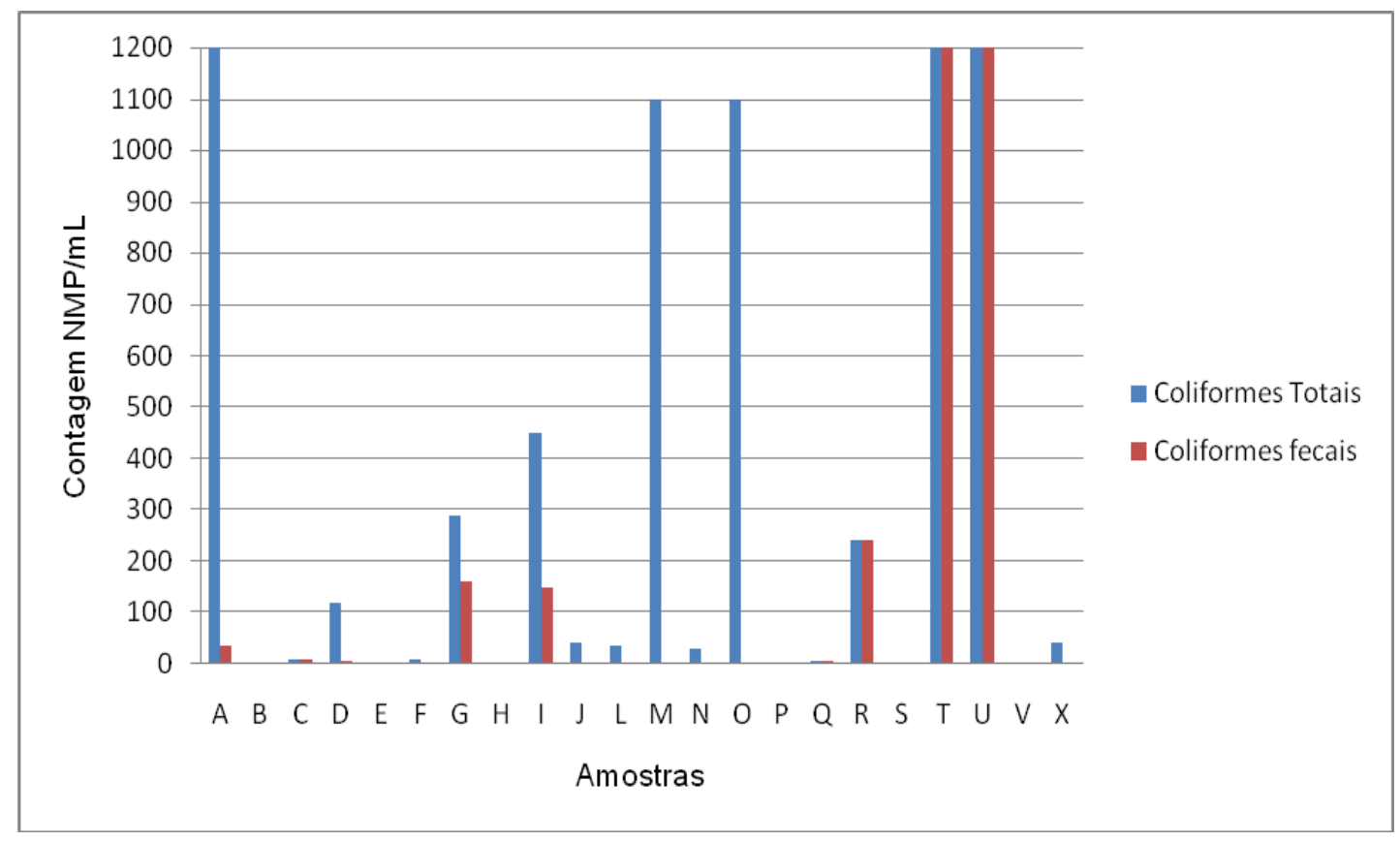

Figura 2 - Contagem de coliformes totais e fecais

Tabela 1 - Contagem de coliformes totais e fecais e detecção de Salmonella sp. 


\begin{tabular}{|c|c|c|c|}
\hline Amostra & $\begin{array}{l}\text { Coliformes totais } \\
(\mathrm{NMP} / \mathrm{mL})\end{array}$ & $\begin{array}{l}\text { Coliformes fecais } \\
(\mathrm{NMP} / \mathrm{mL})\end{array}$ & Salmonella sp.(+/-) \\
\hline A & $>1100$ & 35 & $(-)$ \\
\hline B & 3 & zero & $(-)$ \\
\hline $\mathrm{C}$ & 9,2 & 9,2 & $(-)$ \\
\hline $\mathrm{D}$ & 120 & 7,2 & $(-)$ \\
\hline $\mathrm{E}$ & zero & zero & $(-)$ \\
\hline $\mathrm{F}$ & 9,2 & zero & $(-)$ \\
\hline G & 290 & 160 & $(-)$ \\
\hline $\mathrm{H}$ & zero & zero & $(-)$ \\
\hline $\mathrm{I}$ & 450 & 150 & $(-)$ \\
\hline $\mathrm{J}$ & 43 & 3,6 & $(-)$ \\
\hline $\mathrm{L}$ & 36 & zero & $(-)$ \\
\hline $\mathrm{M}$ & 1100 & zero & $(-)$ \\
\hline $\mathrm{N}$ & 29 & zero & $(-)$ \\
\hline $\mathrm{O}$ & 1100 & zero & $(-)$ \\
\hline $\mathrm{P}$ & 3,6 & zero & $(-)$ \\
\hline $\mathrm{Q}$ & 6,1 & 6,1 & $(-)$ \\
\hline $\mathrm{R}$ & 240 & 240 & $(-)$ \\
\hline S & zero & zero & $(-)$ \\
\hline $\mathrm{T}$ & $>1100$ & $>1100$ & $(-)$ \\
\hline $\mathrm{U}$ & $>1100$ & $>1100$ & $(-)$ \\
\hline V & zero & zero & $(-)$ \\
\hline $\mathrm{X}$ & 43 & 3,6 & $(-)$ \\
\hline
\end{tabular}

Penha et al (2005), em trabalho sobre a caracterização físico-química, microbiológica e sensorial em água de coco envasada pelo processo asséptico constataram a ausência de coliformes totais e fecais, bem como ausência de Salmonella sp. Este fato pode ser explicado pelo processo ao qual a água de coco passa, havendo o emprego de tratamento térmico e eliminação efetiva da microbiota patogênica. $\mathrm{O}$ processo de envase da água de coco no município de Currais Novos acontece de maneira artesanal sendo, por isso, mais susceptível à contaminação.

As contagens de Staphylococcus coagulase positiva apresentaram resultados negativos. Os padrões estabelecidos pela Resolução RDC $n^{\circ} 12$, de 02 de janeiro de 2001, não exigem a análise de Staphylococcus, no entanto, pelo fato das amostras se tratarem de produtos obtidos de maneira artesanal e do risco associado às intoxicações alimentares considerouse relevante tal análise. 
Os resultados de bolores e leveduras e bactérias mesófilas totais foram encontrados com variação de até $1,7 \times 10^{5} \mathrm{UFC} / \mathrm{mL}$ e de $6,0 \times 10 \mathrm{UFC} / \mathrm{mL}$ a $3,0 \times 10^{5} \mathrm{UFC} / \mathrm{mL}$, respectivamente (Tabela 2). Embora não sendo análises obrigatórias pela legislação, os bolores e leveduras e os microrganismos aeróbios mesófilos foram determinados, pois quando presentes em números elevados nos alimentos podem causar deterioração e/ou redução da vida de prateleira. Os resultados encontrados demonstraram qualidade microbiológica insatisfatória, sugerindo falhas durante o processo de envase e/ou conservação da água de coco.

Tabela 2 - Contagem de bolores e leveduras de bactérias mesófilas totais

\begin{tabular}{|c|c|c|}
\hline Amostra & $\begin{array}{l}\text { Contagem de bolores e } \\
\text { leveduras (UFC/mL) }\end{array}$ & $\begin{array}{l}\text { Contagem de mesófilos } \\
\text { totais }(\mathrm{UFC} / \mathrm{mL})\end{array}$ \\
\hline $\mathrm{A}$ & $2,0 \times 10^{3}$ & $3,3 \times 10^{4}$ \\
\hline B & $1,4 \times 10^{2}$ & $1,4 \times 10^{3}$ \\
\hline $\mathrm{C}$ & $2,5 \times 10^{2}$ & $6,6 \times 10^{3}$ \\
\hline D & $1,7 \times 10^{5}$ & $2,5 \times 10^{4}$ \\
\hline $\mathrm{E}$ & $9,2 \times 10^{2}$ & $3,0 \times 10^{5}$ \\
\hline $\mathrm{F}$ & $1,8 \times 10^{4}$ & $4,0 \times 10^{4}$ \\
\hline$G$ & $1,0 \times 10^{4}$ & $2,6 \times 10^{3}$ \\
\hline $\mathrm{H}$ & $3,4 \times 10^{4}$ & $5,6 \times 10^{3}$ \\
\hline I & $6,0 \times 10^{3}$ & INC \\
\hline $\mathrm{J}$ & INC & INC \\
\hline $\mathrm{L}$ & $4,4 \times 10^{3}$ & $3,5 \times 10^{4}$ \\
\hline $\mathrm{M}$ & $2,1 \times 10^{3}$ & $5,7 \times 10^{4}$ \\
\hline $\mathrm{N}$ & $1,2 \times 10^{4}$ & $8 \times 10^{4}$ \\
\hline $\mathrm{O}$ & $2 \times 10^{5}$ & INC \\
\hline $\mathrm{P}$ & $4 \times 10^{3}$ & $5 \times 10^{2}$ \\
\hline Q & $2,2 \times 10^{2}$ & $3,3 \times 10^{4}$ \\
\hline $\mathrm{R}$ & $1,310^{4}$ & $2 \times 10^{5}$ \\
\hline$S$ & $3 \times 10$ & $7,1 \times 10^{2}$ \\
\hline $\mathrm{T}$ & $1,4 \times 10^{3}$ & $2 \times 105$ \\
\hline $\mathrm{U}$ & $4 \times 10^{4}$ & $8,2 \times 10^{4}$ \\
\hline V & zero & $6 \times 10$ \\
\hline $\mathrm{X}$ & $2 \times 10^{3}$ & $6,7 \times 10^{2}$ \\
\hline
\end{tabular}

\section{CONCLUSÕES}

- Das amostras analisadas $22,7 \%$ apresentaram-se fora do padrão estabelecido pela legislação vigente para coliformes fecais; 
- Coliformes totais apresentaram valores altos, sugerindo o contato do fruto com o solo e/ou má higienização durante o processamento;

- Não foram encontrados Staphylococcus coagulase positiva e Salmonella sp. em nenhuma das amostras;

- As altas contagens encontradas para bactérias mesófilas e bolores e leveduras sugerem a necessidade de melhorias durante o processo de envase de água de coco verde resfriada.

\section{REFERÊNCIAS BIBLIOGRÁFICAS}

1. ABREU, Fernando. COMÉRCIO EXTERIOR.... Disponível em: $<$ http://www.sfiec.org.br/noticias/export-aguacoco090505.htm>. Acesso em 03 jan. 2008.

2. ARAGÃO, W. M.; ISBERNER, J. V.; CRUZ, e. M. de O. Água de coco. Aracaju: Embrapa Tubuleiros Costeiros, 2001. 32 p. (Documentos, 24).

3. AROUCHA, E. M. M.; VIANNI, R. Determinação de ácido ascórbico na água de coco por cromatografia líquida e pelo método titulométrico. Revista Ceres, Viçosa, v. 49, n. 283, p. 245-251, 2002.

4. CAMPOS, C.F. SOUZA, P.E.A.; COELHO, J.V.; GLÓRIA, M.M.B.A. Green coconut water quality. Journal of Food Processing and Preservation, v. 20, p. 487-500, 1996.

5. DUARTE, A.C.P., COELHO, M.A.Z.-Identification of peroxidase and tyrosinase ingreen coconut water. Ciência e Tecnologia de Alimentos, v.3, n.5, p. 266-270, 2002.

6. HOFFMAN, F.I.; COELHO, A. R.; MANSOR, A. P.; TAKAHASHI, C. M.; VINTURIM, C. M. Qualidade microbiológica de amostras de água de côco vendidas por ambulantes na cidade de São José do Rio Preto - SP. Revista Higiene Alimentar, São Paulo, v.16, n.97, p. 87-92, jun. 2002.

7. NOGUEIRA et all. Avaliação sensorial de água de coco (Cocos nucifera L) in natura e processada. Revista de biologia e ciências da terra. Limoeiro do Norte, v. 4, n.2, 2004.

8. PENHA, E. M. Características do coco verde para industrialização da água e da polpa gelatinosa. In: CONGRESSO BRASILEIRO DE CIÊNCIA E TECNOLOGIA DE ALIMENTOS, 16., 1998, Rio de Janeiro. Anais... Campinas: SBCTA, 1998. CDROM.

9. PENHA, E. M.; CABRAL, L. M. C; MATTA, V. M. Água de coco. In: FILHO, W. G. V. Tecnologia de bebidas: matéria prima, processamento, BPF/APPCC, legislação e mercado. São Paulo: Edgard Blucher, 2005.

10. SILVA, N. da et ali. Manual de métodos de análise microbiológica de alimentos. 3. ed. São Paulo: Livraria Varela, 2007. 